Check for updates

Cite this: RSC Adv., 2018, 8, 38758

\title{
Colorimetric detection of protein via the terminal protection of small-molecule-linked DNA and unmodified gold nanoparticles
}

\begin{abstract}
Jianwei Zhao, ${ }^{a}$ Cuiping Li, (D) *b Guimin Ma, ${ }^{a}$ Wenhui Hao and Hongxia Jia*a
A novel colorimetric strategy for protein detection was developed based on unmodified gold nanoparticles (AuNPs) and terminal protection from a target protein. A hairpin-structured DNA probe with a biotin modification at the $3^{\prime}$ terminus combined with streptavidin (SA) by the high affinity between biotin and SA and resisted degradation from exonucleases III (Exo III), which selectively digested double-stranded DNA from the 3 '-terminus. The remaining hairpin DNA lost the capacity to protect AuNPs from saltinduced aggregation, resulting in a color change of AuNPs from red to blue. In the absence of SA, Exo III degraded the hairpin DNA into single-stranded DNA, which adsorbed on the surfaces of AuNPs and prevented aggregation, keeping AuNPs with a red color. The state of AuNP aggregation can be discriminated by colorimetry and also can be measured by UV-vis spectroscopy. Our proposed method provided great selectivity and high sensitivity with a detection limit of 0.24 pmol for SA detection. Moreover, the assay avoided modification, enzymatic amplification and special equipment, and also offered the advantages of being simple, cost-effective, and sensitive. This novel strategy holds great promise for the detection of other proteins by small molecule interactions with proteins.
\end{abstract}

Received 2nd September 2018
Accepted 31st October 2018

DOI: $10.1039 / \mathrm{c} 8 \mathrm{ra0} 3314 \mathrm{~g}$

rsc.li/rsc-advances single-stranded DNA (ssDNA) intact. Thus, protein detection is translated into determination of DNA. The method is called terminal protection of small molecule-linked DNA (TPSMLD). ${ }^{4}$ This interesting strategy has been successfully applied to the detection of FITC antibody, ${ }^{5}$ H5N1 antibody, ${ }^{6}$ and folate receptors. $^{7}$

Based on the terminal protection mechanism, numbers of detection methods for proteins have been developed by combining this with fluorescence, electrochemical, and colorimetric techniques. Fluorescence DNA analysis generally requires signal amplification technologies, such as rolling circle amplification and hybridization chain reaction (HCR), and thus realizes higher sensitivity. ${ }^{8}$ In addition, it usually needs fluorescent tags, which leads to a sophisticated procedure, prolonged reaction time, low stability, and high cost., Electrochemical methods commonly need to immobilize ssDNA onto the surface of an electrode which increases complexity. ${ }^{\mathbf{8 b}, \mathbf{1 0}}$ Therefore, the development of a label-free, homogeneous, and simple method for protein assay should be an attractive alternative.

Colorimetric detections have attracted increasing attention on the basis of their simplicity, uncomplicated equipment, and visible color-change to the naked eye after an addition of a target analyte. ${ }^{11}$ Gold nanoparticles (AuNPs) are widely used in colorimetric detections due to their unique optical properties. ${ }^{\mathbf{1 2}}$ AuNPs show red in an aqueous solution and the addition of enough $\mathrm{NaCl}$ can induce aggregation, with concomitant color conversion from red to blue. Single-stranded DNA can adsorb 
onto the surfaces of AuNPs against salt-induced aggregation and keep the red color of AuNPs. Using this property, some methods of protein detection have been proposed, however, they usually require sophisticated modification on the surfaces of AuNPs, which increases experimental difficulty and time. ${ }^{13}$

In this work, incorporation of terminal protection of smallmolecule-linked DNA and unmodified AuNPs developed a label-free, homogenous, and procedure-saving colorimetric detection of protein. A biotin-streptavidin (SA) system, as a typical representative of small molecule-target protein pairs, has been widely used as a model for protein detection and research of the relationship between small molecules and target proteins. SA detection has great significance for researching the interactions between biotin and SA and the related physiological function mechanisms, such as cell development, cell signaling, protein function, and so on. ${ }^{14}$ Here, the biotin-SA system was used as a model to evaluate the method. SA captured a biotin-tethered hairpin DNA probe at the $3^{\prime}$-terminus against digestion of exonuclease III (Exo III), leaving the intact hairpin DNA. Double-stranded hairpin DNA failed to prevent saltinduced aggregation of AuNPs, thus showing blue. In the absence of SA, single-stranded DNA generated from Exo III protected AuNPs from aggregation, keeping a red color. SAdependence on color change can be utilized to quantitatively measure SA amounts.

\section{Results and discussion}

\section{Principle of gold nanoparticle-based colorimetric detection of proteins}

The proposed strategy for protein detection incorporated terminal protection using a double-strand DNA probe against Exo III and aggregation of AuNPs as shown in Fig. 1. A hairpinstructured DNA probe was designed with 15 pairs of complementary bases as the stem and 6 bases as the loop. Furthermore, a biotin was bound to the $3^{\prime}$-terminus of the hairpin DNA probe. Exo III has been verified to selectively digested doublestranded DNA into nucleotides from the $3^{\prime}$-terminus. In the presence of SA, a $3^{\prime}$-terminus biotin-modified hairpin DNA probe combined with SA on the basis of the high affinity between biotin and SA, and thus the hairpin DNA probe was

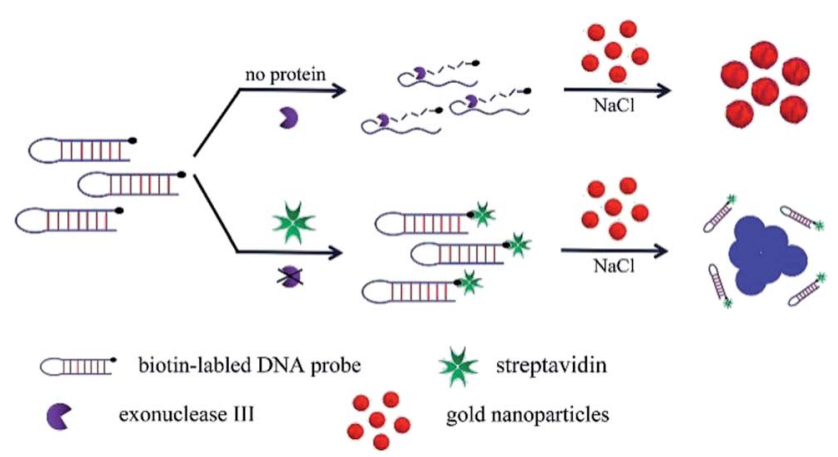

Fig. 1 Schematic illustration of the developed protein detection method. protected from the degradation of Exo III at the $3^{\prime}$-terminus, leaving the intact hairpin DNA probe. In contrast, without SA, the hairpin DNA probe was degraded into nucleotides and single-stranded DNA residuals.

The prepared AuNPs were stably dispersed in an aqueous solution, relying on citrate ion-capped resistance to the van der Waals attraction between AuNPs..$^{15}$ The addition of enough $\mathrm{NaCl}$ curtained the repulsion between AuNPs and induced aggregation, accompanied by the conversion of color from red to blue. Single-stranded DNA could absorb onto the surfaces of AuNPs against salt-induced aggregation. In our work, with SA, a double-stranded hairpin DNA probe failed to adsorb on the surfaces of AuNPs, leading to salt-induced aggregation of AuNPs with concomitant color change from red to blue. On the contrary, in the absence of SA, the generated single-stranded DNA residuals from the degradation of Exo III could adsorb onto the surfaces of AuNPs to prevent aggregation. AuNPs aggregation causes a shift of the maximum absorption wavelength from 525 (red) to $675 \mathrm{~nm}$ (blue). The absorbance ratio of $A_{675} / A_{525}$ is a positive correlation with the concentration of SA, allowing quantitative measurement of SA.

\section{Investigation of optimized experimental conditions for sensitive detection of protein}

To obtain optimal experimental conditions, four important reaction parameters, including the amount and reaction time of Exo III, concentrations of the hairpin DNA probe and $\mathrm{NaCl}$, were thoroughly investigated.

Without terminal protection, Exo III can catalyze the hydrolysis of duplex DNA from the 3 -hydroxyl terminus, and thus the amount and reaction time of Exo III was directly associated with removal efficiency of the mononucleotide in double-stranded DNA, and further related to AuNPs aggregation. With AuNPs aggregation, the absorbance at $525 \mathrm{~nm}$ decreased gradually and meanwhile increased at $675 \mathrm{~nm}$. Therefore, the absorbance ratio $A_{675} / A_{525}$ was used to evaluate the state of AuNPs aggregation. Various amounts of Exo III, ranging from 2 to $10 \mathrm{U}$, were tested and the results are shown in Fig. 2. According to the colorimetric photos (Fig. 2A), an increase in Exo III gradually caused the color conversion of AuNPs from blue to red in the absence of SA, while the color of AuNPs exhibited a slight transition in the presence of SA. As seen, the colors showed the greatest difference at 8 and $10 \mathrm{U}$ of Exo III and the largest distinction of absorbance ratio at 675 and $525 \mathrm{~nm}$ was also observed at 8 and $10 \mathrm{U}$ of Exo III with and without SA (Fig. 2B). Considering the cost, 8 U Exo III was selected for subsequent experiments. Additionally, the digestion time of Exo III also affected the performance of the method. Fig. 3 shows the effect of varying reaction times with Exo III on the aggregation of AuNPs. It was observed that as reaction time was prolonged (from 30 to $120 \mathrm{~min}$ ), the color of AuNPs changed from blue to red in the absence of SA, indicating that extended digestion time can release more single-stranded DNA to the solution and stabilize AuNPs. In contrast, after an addition of SA, extended reaction time induced no remarkable color changes, suggesting that terminal protection from SA prevented 

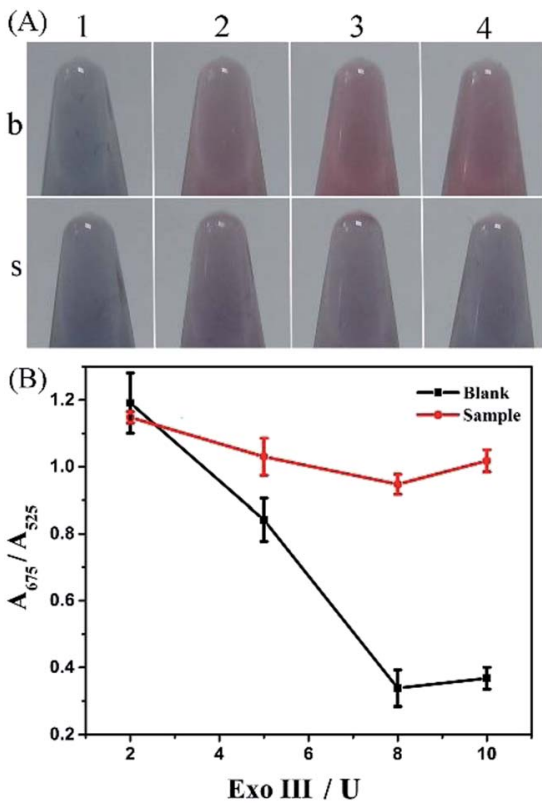

Fig. 2 Effect of Exo III amounts on AuNPs aggregation in the terminal protection assay. (A) Colorimetric results of increasing amounts of Exo III with (s) and without SA (b). 1-4 correspond to 2, 5, 8, and $10 \cup$ of Exo III. (B) The absorbance ratio $A_{675} / A_{525}$ in the presence and absence of SA. Blank, without SA; sample, with SA. Error bars represent standard deviation from three repeated experiments.
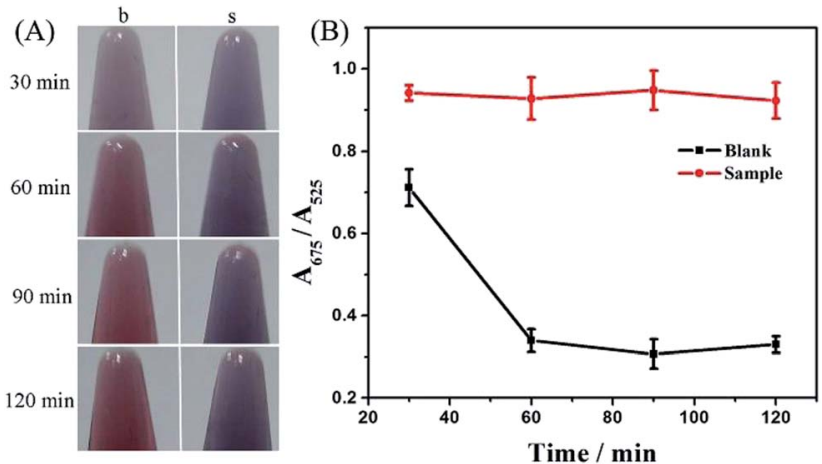

Fig. 3 Effect of the reaction time of Exo III on AuNPs aggregation in a terminal protection assay. (A) Colorimetric results of increasing reaction time of Exo III with (s) and without SA (b). (B) The absorbance ratio $A_{675} / A_{525}$ in the presence and absence of SA. Blank, without SA; sample, with SA.

the degradation of Exo III and AuNPs realized salt-induced aggregation. With and without SA, the color was more obviously different after 90 and $120 \mathrm{~min}$ of digestion. However, $90 \mathrm{~min}$ was more favorable, due to a greater gap in the absorbance ratio. Therefore, $90 \mathrm{~min}$ was chosen as the optimum digestion time of Exo III.

Amount of a hairpin DNA probe also was a key factor in the reaction system. Insufficient DNA probe lost the ability to generate enough single-stranded DNA against highconcentration salt-induced aggregation of AuNPs, and also failed to meet the combination with abundant SA. When DNA probes were in excess, Exo III degraded residual probes and produced single-stranded DNA against AuNPs aggregation, and thus insufficient SA lost its role in terminal protection. We tested the system with $40,60,80$, and 100 pmol DNA probes, and found that as the concentration of DNA probe increased, the color of AuNPs changed from blue to red in the absence of $\mathrm{SA}$, while they remained blue from 40 to $80 \mathrm{pmol}$ with a slight tendency of turning red in the presence of SA (Fig. 4). At higher concentrations of the probe (100 pmol), AuNPs resisted saltinduced aggregation and exhibited red color due to plenty of single-stranded DNA produced by digesting excess residual probes, suggesting an excess of DNA probes. Meanwhile, the largest distinction of absorbance ratio was also observed with a 80 pmol DNA probe. Taken together, 80 pmol was the optimal selection.

$\mathrm{NaCl}$ concentration was also directly related to aggregation of AuNPs. Fig. 5 shows that the difference in both color and absorbance ratio of $A_{675} / A_{525}$ was the greatest at $0.15 \mathrm{~mol} \mathrm{~L}^{-1}$ $\mathrm{NaCl}$. A lower concentration of $\mathrm{NaCl}\left(0.1 \mathrm{~mol} \mathrm{~L}^{-1}\right)$ was unable to induce significant aggregation, while a higher concentration $\left(0.25 \mathrm{~mol} \mathrm{~L}^{-1}\right)$ resulted in aggregation in the presence and absence of SA. Therefore, $0.15 \mathrm{~mol} \mathrm{~L}^{-1} \mathrm{NaCl}$ was used in the following experiments.

\section{Sensitivity investigation}

Under the optimized conditions, increasing amounts of SA were added to co-incubate with the hairpin DNA probe according to the description in the Experimental section. Through analysis with a UV-Vis spectrophotometer, spectra were obtained as
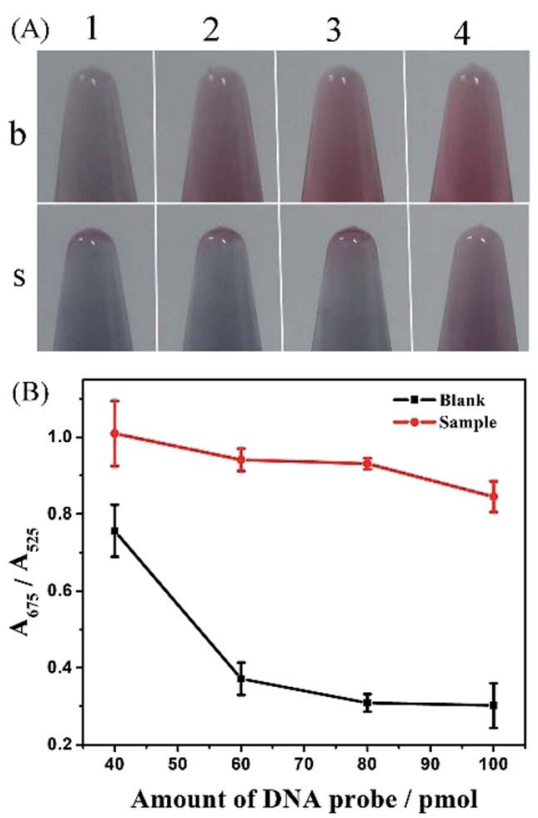

Fig. 4 Effect of amounts of hairpin DNA probes on AuNPs aggregation in the terminal protection assay. (A) Colorimetric results of increasing amounts of hairpin DNA probes with (s) and without SA (b). 1-4 correspond to 40,60, 80, and 100 pmol of hairpin DNA probes. (B) The absorbance ratio $A_{675} / A_{525}$ in the presence (sample) and absence (blank) of SA. 
(A)

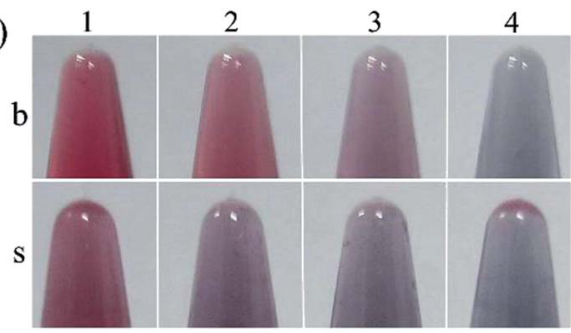

(B)

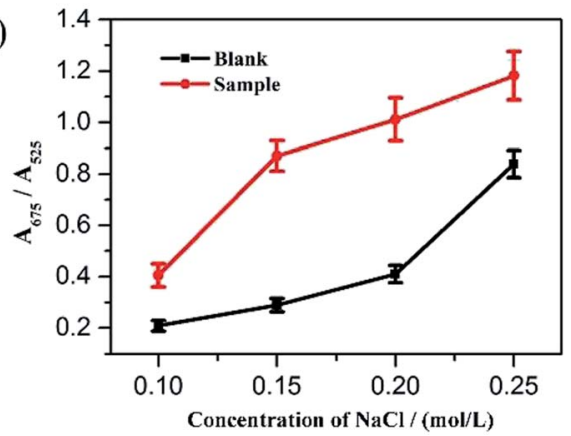

Fig. 5 Effect of $\mathrm{NaCl}$ concentrations on AuNPs aggregation in the terminal protection assay. (A) Colorimetric results of increasing $\mathrm{NaCl}$ concentrations with (s) and without $\mathrm{SA}(\mathrm{b}) .1-4$ correspond to $0.1,0.15$, 0.2 , and $0.25 \mathrm{~mol} \mathrm{~L}-1 \mathrm{NaCl}$. (B) The absorbance ratio $A_{675} / A_{525}$ in the presence (sample) and absence (blank) of SA.

shown in Fig. 6. With increased amounts of SA, the color of the AuNPs solution showed a gradual conversion from red to blue, and consistently the maximum absorption wavelength also migrated from 525 to $675 \mathrm{~nm}$, indicating that more SA protected
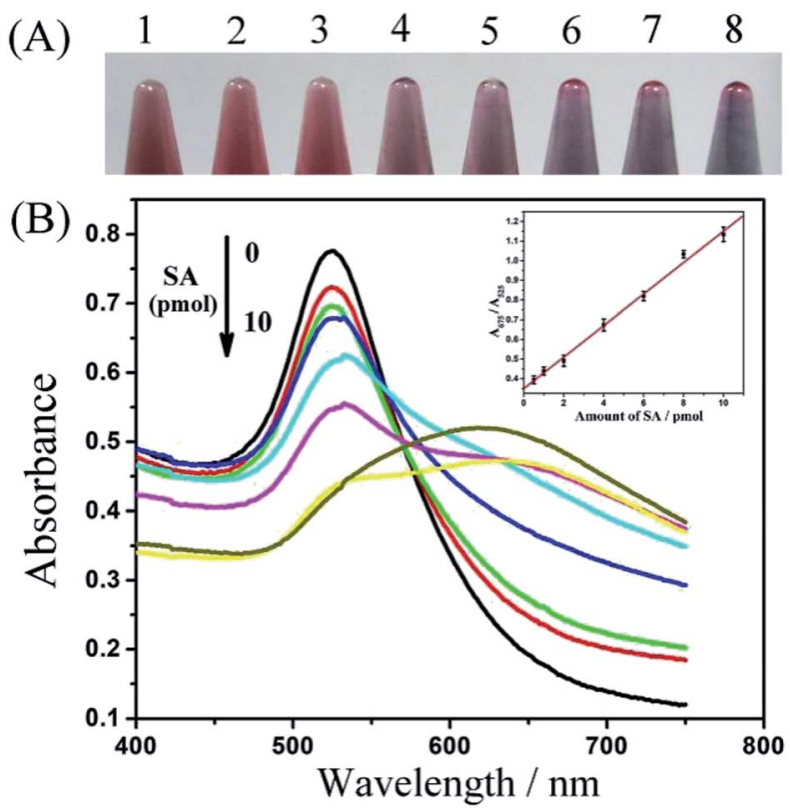

Fig. 6 Colorimetric and absorption spectrographic analysis of varying amounts of SA. (A) Different amounts of SA induced various degrees of AuNPs aggregation. 1-8 correspond to $0,0.5,1,2,4,6,8$, and $10 \mathrm{pmol}$ $\mathrm{SA}$. (B) Absorption spectra of AuNPs in response to increasing amounts of SA (0-10 pmol). Insert: calibration curves of SA analysis. the 3 -terminal of hairpin DNA probe from degradation by Exo III and not enough single-stranded DNA was generated to resist salt-induced aggregation. These results are in accord with the preconceived principle of the method. By analysis of the alteration in relative absorption ratio $A_{675} / A_{525}$ with respect to SA amounts, a linear relationship was obtained in the range from 0.5 to $10 \mathrm{pmol}$. The linear equation was $Y=0.080 X+0.35$ with a correlation coefficient of 0.996 , where $X$ represented the amounts (pmol) of SA (the inset in Fig. 6B). According to the $3 \sigma$ rule, the detection limit was estimated to be $0.24 \mathrm{pmol}$ (corresponding to approximately $0.63 \mathrm{nM} \mathrm{SA}$ in $375 \mu \mathrm{L}$ of solution (three-fold dilution of $125 \mu \mathrm{L}$ )). This sensitivity of protein detection was comparable or higher than some TPSMLD-based and fluorescence-based methods (Table 1). Although more sensitive approaches have been reported, they often required complicated modifications of AuNPs or other material, expensive fluorophore labelling, long-time enzymatic amplification, and special equipment. Our proposed strategy is a simple, costeffective, and sensitive detection method.

\section{Selectivity of the assay}

To evaluate specificity of the terminal protection, six other proteins, including trypsin, glucose oxidase, chymotrypsin, pepsin, lysozyme, and human serum albumin (HSA) were examined using the proposed strategy. The maximum amount in the linear range of SA analysis, namely $10 \mathrm{pmol}$, was utilized to perform the test except with HSA (1 pmol). As shown in colorimetric experiments, the color of AuNPs solution showed blue from the terminal protection of SA, indicating the aggregation of AuNPs. In contrast, after an addition of five other proteins, the AuNPs solution stayed red, revealing the failure of terminal protection (Fig. 7A). To compare the ratio $(R)$ of absorbance at 675 and $525 \mathrm{~nm}$, we set the value of $\left(R_{\mathrm{SA}}-R_{\text {blank }}\right)$ as 1 and it was found the relative ratio $\left(R_{\text {protein }}-R_{\text {blank }}\right)$ of other proteins was less than 0.1 (Fig. 7B). These results suggested that the proposed strategy showed high selectivity.

To further ascertain the application of the developed method in a complex matrix, a mixture containing 2 pmol of SA, trypsin, glucose oxidase, chymotrypsin, pepsin, lysozyme, and 0.2 pmol of HSA, respectively, was used to quantitatively detect target SA. After spiking 3 or 5 pmol SA into the complex matrix, the results were obtained. The recovery rates were $105.8 \%$ and $106.4 \%$ at 3 and 5 pmol standard addition, respectively. These results

Table 1 A comparison of the detection limits for protein detection between this work and TPSMLD-based and fluorescence-based methods

\begin{tabular}{lll}
\hline Target protein & Detection limit & Reference \\
\hline Thrombin & $11 \mathrm{nM}$ & $16 a$ \\
Caspase-3 & $1.4 \mathrm{nM}$ & $16 b$ \\
SA & $2.4 \mathrm{nM}$ & $16 c$ \\
SA & $2.6 \mathrm{nM}$ & $10 c$ \\
Avidin & $1.29 \mathrm{nM}$ & $8 d$ \\
SA & $0.63 \mathrm{nM}$ & This work
\end{tabular}




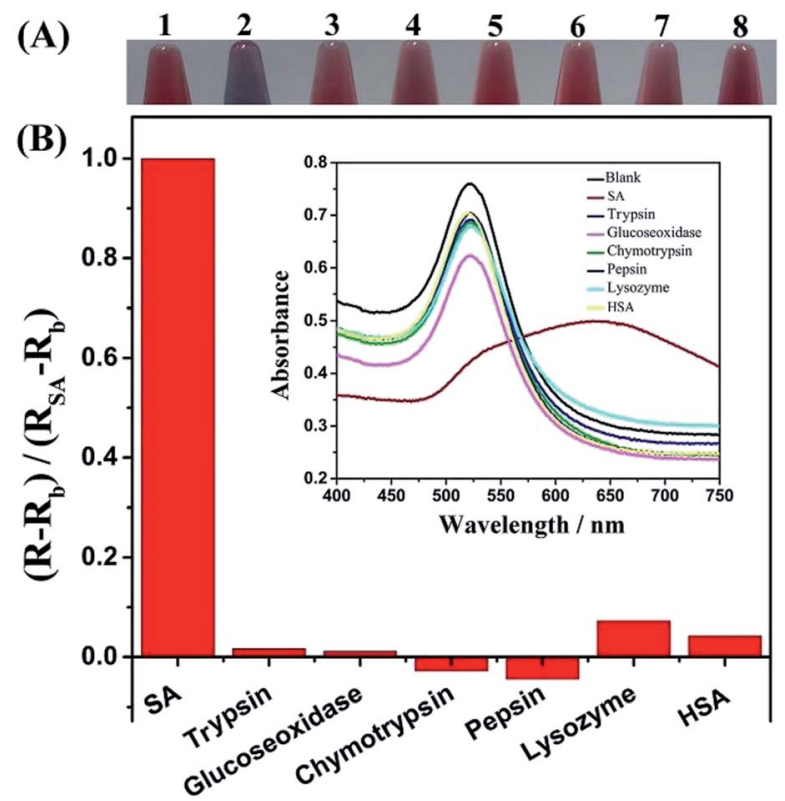

Fig. 7 Selectivity of the proposed assay toward SA. (A) Target protein (SA) and other interfering proteins induced different color changes of AuNPs solutions. 1-8 represent blank, SA, trypsin, glucose oxidase, chymotrypsin, pepsin, lysozyme and HSA, respectively. (B) Absorption spectra differentiated $S A$ and other protein. Insert: absorption spectra of AuNPs solution via the pretreatment of $\mathrm{SA}$ and other proteins. $R-R_{\mathrm{b}}$ $=\left(A_{675} / A_{525}\right)_{\text {protein }}-\left(A_{675} / A_{525}\right)_{\text {blank }}, R_{\mathrm{SA}}-R_{\mathrm{b}}=\left(A_{675} / A_{525}\right)_{\mathrm{SA}}-\left(A_{675}\right)$ $\left.A_{525}\right)_{\text {blank. }}$. The amounts of SA and other proteins were 10 pmol except HSA (1 pmol).

showed that our developed method can be utilized in a complex matrix.

\section{SA detection in serum}

The possibility of the proposed colorimetric method being applied to real samples was investigated by detecting SA in human serum. The detection process was the same as in the

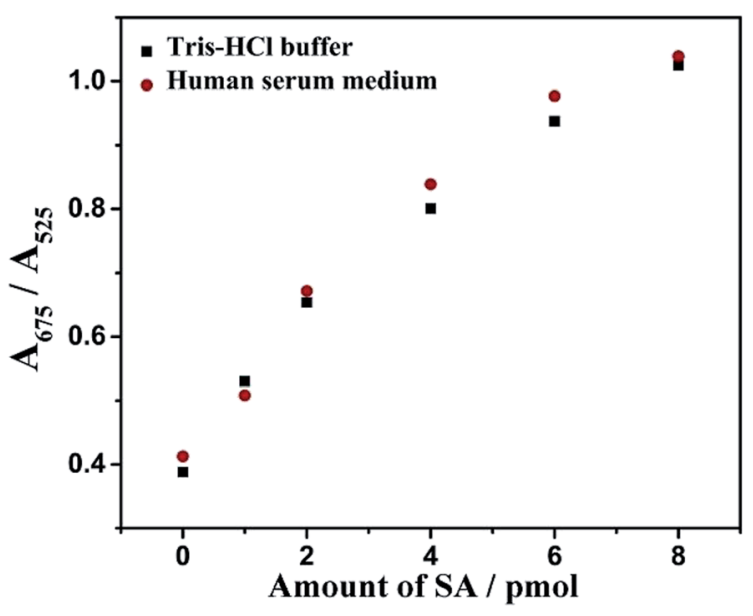

Fig. 8 Absorbance ratio assay for SA in human serum. Other conditions are performed according to the experimental procedure described in the Experimental section.
Tris-HCl buffer and the results are shown in Fig. 8. Absorbance signals produced by the same amount of SA in human serum showed a similar pattern to that produced in Tris-HCl buffer. Thus, the proposed colorimetric method had good compatibility with real biological samples.

\section{Conclusions}

In summary, a novel sensor for proteins was developed by the Exo III-aided terminal protection of small-molecule-linked DNA and an AuNP colorimetric system. The strategy omits the timeconsuming modification of AuNP surfaces and avoids enzymatic amplification, and thus saves time and costs. Additionally, it only needs visual inspection or simple analysis by a UVvis spectrophotometer to detect protein, so it is simple and easy to operate. Moreover, the assay shows excellent resistance to nonspecific proteins, great recovery in a complex matrix, and good compatibility with real biological samples. In view of the above advantages, this novel strategy holds great potential for the detection of proteins for disease diagnosis and therapy.

\section{Experimental section}

\section{Materials and apparatus}

Tetrachloroauric acid $\left(\mathrm{HAuCl}_{4} \cdot 4 \mathrm{H}_{2} \mathrm{O}\right)$ and trisodium citrate were purchased from Sinopharm Chemical Reagent Co. (Shanghai, China). Duplex-specific exonucleases (Exo III) was obtained from New England Biolabs (USA). The biotin-labelled DNA probe sequences was custom synthesized by Shanghai Sangon Biological Engineering Technology and Services Co., Ltd. (Shanghai, China). Streptavidin (SA) and other interfering proteins, including chymotrypsin, glucose oxidase, pepsin, trypsin, and lysozyme, were purchased from Shanghai Sangon Biological Engineering Technology and Services Co., Ltd. (Shanghai, China). HSA and human serum were obtained from Beijing Solarbio Science and Technology Co., Ltd. (Beijing, China). This study was performed in strict accordance with the "Guide to scientific and technological academic standards in colleges and universities" of Hebei University for the use of human subjects (published on May 28, 2015, Baoding, China). There was no ethical conflict throughout the experiment.

The biotin-tagged DNA probes were dissolved in sterile water and frozen at $-20{ }^{\circ} \mathrm{C}$. Phosphate buffer (PBS, $\mathrm{pH}=7.4$, $\left.0.1 \mathrm{~mol} \mathrm{~L}^{-1}\right)$ and Tris-HCl buffer $\left(\mathrm{pH}=7.3,0.5 \mathrm{~mol} \mathrm{~L}^{-1}, \mathrm{MgCl}_{2}\right.$, $67 \mathrm{mmol} \mathrm{L}^{-1}$ ) solutions were prepared in our laboratory. All other reagents were of analytical grade and all solutions were prepared using ultrapure water with an electric resistance of 18.2 $\mathrm{M} \Omega$.

The reaction for SA detection was performed on a 2720 Thermal Cycler (Applied Biosystems, Thermo Fisher Scientific Inc., USA). The photographs recording colors of AuNPs were obtained with an IXUS 230HS digital camera (Canon, China Co., Ltd.). The UV-Vis adsorption spectra were recorded with a TU1901 double-beam UV-Visible spectrophotometer (Beijing Purkinje General Instrument Co., Ltd., China). The ratio of absorbance at wavelengths of 525 and $675 \mathrm{~nm}$ was calculated to 
evaluate optimized reaction conditions and the performance of the assay.

The sequence of the biotin-DNA probe was shown as follows: ssDNA probe $\left(5^{\prime} \rightarrow 3^{\prime}\right)$ : TGC CTG GCT CCC TGT ATG CCA ACA GGG AGC CAG GCA-biotin.

\section{Preparation of AuNPs}

The gold nanoparticle (AuNP) ( $\sim 13 \mathrm{~nm}$ in diameter) solution was prepared according to a previously reported method. ${ }^{17}$ In brief, $4.1 \mathrm{~mL}$ of $1 \% \mathrm{HAuCl}_{4}$ and $95.9 \mathrm{~mL}$ double distilled water were added to a three-necked flask equipped with a condenser and heated to boiling with vigorous stirring. Immediately, $10 \mathrm{~mL}$ of sodium citrate $(38.8 \mathrm{mM})$ was added to the boiling solution, accompanying the conversion of its color to pale yellow, and then further to burgundy. Thereafter, the mixed solution was kept boiling for $10 \mathrm{~min}$ and then heating was halted. After that, the solution was stirred for another $15 \mathrm{~min}$ and cooled to room temperature.

\section{Detection of streptavidin (SA) protein based on AuNPs}

To employ terminal protection to analyse the SA protein, a biotin-labelled ( $3^{\prime}$-end) hairpin-structured DNA was used to specifically bind with SA. The reaction was performed by the addition of an optimized amount of hairpin DNA and various concentrations of SA in $50 \mathrm{mM}$ Tris- $\mathrm{MgCl}_{2}$ buffer solution, with the total system of $10 \mu \mathrm{L}$, SA being replaced with equal volumes of ultrapure water in the control experiment (blank). All samples were incubated for $30 \mathrm{~min}$ at $37{ }^{\circ} \mathrm{C}$ to accomplish the combination of SA and biotin. Then, $8 \mathrm{U}$ Exo III was added, and the mixture was incubated for $90 \mathrm{~min}$ at $37{ }^{\circ} \mathrm{C}$ to digest the hairpin-structured DNA. The digestion reaction was terminated by heating at $85{ }^{\circ} \mathrm{C}$ for $20 \mathrm{~min}$. The resultant solution was transferred to $100 \mu \mathrm{L}$ of AuNPs solution and incubated at room temperature for $10 \mathrm{~min}$ to allow complete interaction between ssDNA and AuNPs. Following that, $12.5 \mu \mathrm{L}$ of $10 \times$ PBS $(100 \mathrm{mM}$, $1.5 \mathrm{~mol} \mathrm{~L}^{-1} \mathrm{NaCl}$ ) was added to the above mixture and the reaction system increased to $125 \mu \mathrm{L}$. After blending the solution well, the color was recorded by a digital camera and the absorption spectra was measured by a UV-Vis spectrophotometer after a three-fold dilution.

To evaluate the specificity of terminal protection, other interfering proteins, such as lysozyme, chymotrypsin, pepsin, trypsin, glucose oxidase and HSA, were analyzed under the same conditions as the detection of SA, respectively.

\section{Analysis of recovery in complex matrix}

The complex matrix contained 2 pmol of SA, lysozyme, chymotrypsin, pepsin, trypsin, glucose oxidase and $0.2 \mathrm{pmol}$ HSA, respectively, and 80 pmol of biotin-hairpin-DNA was used in $50 \mathrm{mM}$ Tris- $\mathrm{MgCl}_{2}$ buffer solution. Afterwards, 3 or $5 \mathrm{pmol}$ of standard SA were added into the complex matrix to assess recovery in $10 \mu \mathrm{L}$ of the reaction system. The experimental procedure was the same as with the detection of SA under the optimized conditions.

\section{Detection of SA in serum}

The reaction was performed by the addition of an optimized amount of hairpin DNA with various concentrations of SA and 1 $\mu \mathrm{L} 1 \%$ human serum solution in $10 \mu \mathrm{L}$ of Tris-HCl buffer. SA was replaced with an equal volume of ultrapure water in the control experiment (blank), and other conditions and following processes of the reaction were the same as aforementioned. Finally, the color was recorded by a digital camera and the absorption spectra was measured by a UV-Vis spectrophotometer after a three-fold dilution.

\section{Conflicts of interest}

There are no conflicts of interest to declare.

\section{Acknowledgements}

The project is supported by the National Natural Science Foundation of China (21707027), the Natural Science Foundation of Hebei Province (B2016201052), the Natural Science Foundation of Hebei Education Department (QN2017024) and China Postdoctoral Science Foundation (2017M621094).

\section{Notes and references}

1 (a) Y. Tan, Q. Guo, X. Zhao, X. Yang, K. Wang, J. Huang and Y. Zhou, Biosens. Bioelectron., 2014, 51, 255-260; (b) C. M. Tyrakowski and P. T. Snee, Anal. Chem., 2014, 86, 2380-2386.

2 (a) Y. Q. Lv, Y. T. Qin, F. Svec and T. W. Tan, Biosens. Bioelectron., 2016, 80, 433-441; (b) J. Verbarg, O. Hadass, P. D. Olivo and A. Danielli, Sens. Actuators, B, 2017, 241, 614-618.

3 (a) X. Xiang, J. Shi, F. Huang, M. Zheng, Q. Deng and J. Xu, Biosens. Bioelectron., 2015, 74, 227-232; (b) Z. Zhang, X. Xia, X. Xiang, F. Huang and L. Han, Sens. Actuators, B, 2017, 249, 8-13; (c) Y. He and B. Jiao, RSC Adv., 2015, 5, 101327101332.

4 Z. Wu, Z. Zhen, J. H. Jiang, G. L. Shen and R. Q. Yu, J. Am. Chem. Soc., 2009, 131, 12325-12332.

5 Z. Wu, H. Wang, M. Guo, L. J. Tang, R. Q. Yu and J. H. Jiang, Anal. Chem., 2011, 83, 3104-3111.

6 X. F. Wei, L. Y. Zheng, F. Luo, Z. Y. Lin, L. H. Guo, B. Qiu and G. N. Chen, J. Mater. Chem. B, 2013, 1, 1812-1817.

7 (a) X. Gong, W. Zhou, Y. Chai, Y. Xiang and R. Yuan, RSC $A d v$., 2014, 5, 6100-6105; (b) L. J. Ou, H. B. Wang and X. Chu, Analyst, 2013, 138, 7218-7223.

8 (a) H. Shi, X. Mao, X. Chen, Z. Wang, K. Wang and X. Zhu, Biosens. Bioelectron., 2017, 91, 136-142; (b) G. F. Wang, X. P. He, L. Wang and X. J. Zhang, Biosens. Bioelectron., 2013, 42, 337-341; (c) C. Y. Lee, H. Y. Kim, S. Kim, K. S. Park and H. G. Park, Analyst, 2018, 143, 2023-2028; (d) W. Wu, W. Pan, D. Yu, Z. Yuan, Y. Qin, Y. Lu, T. Zhang and J. Zhou, Analyst, 2018, 143, 829-832. 
9 (a) Y. He, X. J. Xing, H. W. Tang and D. W. Pang, Small, 2013, 9, 2097-2101; (b) C. H. Chen, X. Xiang, Y. F. Liu, G. H. Zhou, X. H. Ji and Z. K. He, Biosens. Bioelectron., 2014, 58, 205-208. 10 (a) H. B. Wang, H. D. Zhang, S. P. Xu, T. Gan, K. J. Huang and Y. M. Liu, Sens. Actuators, B, 2014, 194, 478-483; (b) Y. Cao, S. Zhu, J. Yu, X. Zhu, Y. Yin and G. Li, Anal. Chem., 2012, 84, 4314-4320; (c) Y. He and B. Jiao, Microchim. Acta, 2016, 183, 3183-3189.

11 J. Zhao, S. S. Hu, X. X. Chen, B. Zhang, K. M. Wang and X. J. Liu, Sens. Actuators, B, 2014, 202, 1243-1247.

12 (a) H. Shi, L. Yang, X. Zhou, J. Bai, J. Gao, H. Jia and Q. Li, Microchim. Acta, 2016, 184, 1-7; (b) C. C. Chang, C. Y. Chen, T. L. Chuang, T. H. Wu, S. C. Wei, H. Liao and C. W. Lin, Biosens. Bioelectron., 2016, 78, 200-205.
13 R. D. Li, B. C. Yin and B. C. Ye, Biosens. Bioelectron., 2016, 86, 1011-1016.

14 (a) N. Ohoka, K. Nagai, T. Hattori, K. Okuhira, N. Shibata, N. Cho and M. Naito, Cell Death Dis., 2014, 5, e1513; (b) H. Wang and C. Yan, Neoplasia, 2011, 13, 611-619; (c) H. B. Wang, H. D. Zhang, Y. Chen and Y. M. Liu, Biosens. Bioelectron., 2015, 74, 581-586.

15 Y. Qi and B. Li, Chem.-Eur. J., 2011, 17, 1642-1648.

16 (a) M. Wu, E. Petryayeva and W. R. Algar, Anal. Chem., 2014, 86, 11181-11188; (b) H. J. Kang, J. H. Kim and S. J. Chung, Biosens. Bioelectron., 2015, 67, 413-418; (c) Y. He and B. Jiao, Microchim. Acta, 2016, 183, 3303-3309.

17 K. C. Grabar, R. G. Freeman, M. B. Hommer and M. J. Natan, Anal. Chem., 1995, 67, 735-743. 